\title{
STEP BY STEP PROCESS FROM LOGIC MODEL TO CASE STUDY METHOD AS AN APPROACH TO EDUCATIONAL PROGRAMME EVALUATION
}

\author{
MICHAEL E. KALU AND KATHLEEN E. NORMAN \\ (Received 1, February 2018; Revision Accepted 27, February 2018)
}

\begin{abstract}
Logic models and case study approach to programme evaluation have proven effective in evaluating educational programmes. However, there is no article that has described a step by step process of how a logic model can inform the choice of a case study methodology. In this article, we used the clinical components of a bridging programme in Canada to illustrate the step by step process of logic model to case study methodology. We provided a background to the bridging programme, steps for designing programme evaluation logic model, and subsequently described how programme evaluation would inform the choice of case study methodology. We further described case study methodology ranging from stating the evaluation questions, epistemological position, study proposition and unit of selection, sampling techniques/types, data collection and analysis. In closing, we provided highlights of how to link the evaluation process back to the logic model developed.
\end{abstract}

KEYWORDS: Programme evaluation, logic model, educational programmes, case study methodology

\section{INTRODUCTION}

Programme evaluation is an essential tool for checking the value of either a whole programme or some aspect of a programme (Psoavac \& Carey, 2007). Programme evaluation processes have been used with regard to educational programmes. However, the extent to which the educational evaluators achieve both the evaluation goals as well as the educational goals and objectives depends on the theoretical frameworks or models that inform their evaluation (Owston, 2008). Logic model is one of the frameworks used in evaluating educational programmes. Logic model supports the assumption that evaluation of an educational programme should be goal-oriented but should also focus on a change process (Frye \& Hemmer, 2012). Logic models are either narrative or graphic depictions of reality processes of a programme. These processes are built following a problem (situation) in a given context. The logic model provides links between the situation (problem) and processes employed in solving the problem (Fitzpatrick, Sanders \& Worthen, 2004). The processes are generally explained in four levels: input, activities, output and outcome. However, for an explicit demonstration of how the processes helped solve the situations, different scholars have suggested sub-division of some of the four levels (Frechtling, 2007; McLaughlin \& Jordan, 2015). Input refers to resources which could be human or financial resources and other necessary resources to support the programme. Activities are those events that produce the output. The output consists of the products and services available for the customers. The customers are the users of the products/services produced at the output level. The outcomes are benefits or

Michael E Kalu, School of Rehabilitation Science, McMaster University, Hamilton, ON, Canada.

Kathleen E. Norman, School of Rehabilitation Therapy, Queens University, Kingston, ON Canada.

(C) 2018 Bachudo Science Co. Ltd. This work is licensed under Creative Commons Attribution 4.0 International license. 
changes resulting from activities and output. When the outcome is closely related to the output, it is called short-term outcome. The further application of the short-term outcome is described as an intermediate outcome. The longterm outcome describes the overall impact of the programme. Logic model is often the choice of programme evaluation model for educators because $(a)$ it is used to establish relationships between programme components to programme context (Frechtling, 2007), (b) it serves as a continuous tool for both programme planning and evaluation (Fitzpatrick et al., 2004), and (c) it not only follows a goal-oriented approach but also focuses on the change process (Frye \& Hemmer, 2012).

Evidence has shown that logic model is an easy model that both novice and expert educational programme evaluators can use (Frye \& Hemmer, 2012; McLaughlin \& Jordan, 2015). Cooksy, Gill, \& Kelly (2001) described the use of logic model as an integrative framework for a multi method evaluation of delivery of a school curriculum. However, their article focused on how logic models facilitate the process of triangulation in qualitative methodology. There is no article that has explained how novice educational programme evaluators would progress from logic model to a method of inquiry- case study approach. Therefore, we aim to provide (a) step by step process of how logic model can inform an evaluation of a health-related educational programme, and (b) how the developed logic model can inform the choice of a case study methodology. Throughout this article, we used a hypothetical clinical component of a bridging programme for internationally educated health professionals (IEHPs) in a new country as a project evaluation example to illustrate the step by step process of how a logic model can inform the choice of case study methodology as a programme evaluation method. The first section of this article provides steps for designing programme evaluation logic models for the bridging programme. The second section describes how to develop a case study methodology from evaluation questions from the components of logic models developed in section 1. This article concludes by providing a sequential step for developing logic model to choosing a (case study methodology.
BACKGROUND ABOUT THE INTERNATIONALLY EDUCATED HEALTH PROFESSIONAL BRIDGING (IEHPB) PROGRAMME

We based our hypothetical programme on the Ontario Internationally Educated Physical Therapist Bridging Program (Switzer-Mclntyre, Bonnyman \& Quesnel, 2015) although have changed details in order to make our model more generic and applicable. The bridging programme is an educational programme that aims to help internationally educated health professionals (IEHPs) bridge the academic and professional gap from their prior education and experience to a different cultural context in a new country, in this case Canada. IEHPs in this context are members of a healthcare profession such as nursing, physiotherapy, occupational therapy, or medicine who received their entry-level training outside of Canada. A main element of the bridging programme is to prepare the IEHPs for any examinations they must pass for their respective professional examinations before being allowed to practise as an independent professional in the new country. Thus, the bridging programme helps facilitate the IEHPs' entry into the workforce of the country to which they have migrated. The bridging programme goal could be stated as-to enhance learners' professional and clinical competencies in order to facilitate success as an autonomous/independent practitioner in the healthcare system-Admission into the programme is determined by the abilities of the IEHPs assessed by the bridging programme committee. The bridging programme's unique feature is the opportunity for IEHPs to attend clinical internships, under the supervision of a clinical preceptor. The clinical internships provide opportunity for learners to refresh their skills and integrate clinical reasoning in the new country's context as well as exposure to the healthcare workplace practice models in the new country.

\section{STEPS FOR DESIGNING PROGRAMME EVALUATION LOGIC MODEL FOR THEBRIDGING PROGRAMME. \\ McLaughlin \& Jordan (2015) suggested a five- step process of developing logic model: (i) collecting the relevant information; (ii) describing the problem of the programme; (iii) defining the elements of the logic models in Table 1; (iv) constructing the logic model; and (v) verifying the model.}


Table 1: Elements of the components of a programme evaluation logic model for Internationally Educated Healthcare Professional Bridging Program

\begin{tabular}{|c|c|c|c|c|c|c|}
\hline Resources & Activities & Output & Customers reach & Outcomes & & \\
\hline $\begin{array}{l}\text {-Finances (Budget) } \\
\text {-Clinical experience } \\
\text { materials } \\
\text {-Qualified clinical } \\
\text { instructors } \\
\text { Clinic characteristics } \\
\text {-Documents (policy and } \\
\text { bridging programme) } \\
\text {-Administrative data }\end{array}$ & $\begin{array}{l}\text { At the programme development } \\
\text {-Funding application } \\
\text {-Admission criteria } \\
\text {-Criteria for choosing clinics as a } \\
\text { clinical placement center. } \\
\text {-Developing clinical programme } \\
\text { guidelines } \\
\text { Choice of clinical performance tool } \\
\text { During the programme } \\
\text {-Clinic activities the clinical } \\
\text {-Evaluating performance of the learners }\end{array}$ & $\begin{array}{l}\text { At the programme development } \\
\text {-Established admission and clinics } \\
\text { criteria. } \\
\text {-Produce clinical guidelines and } \\
\text { clinical performance tool } \\
\text { During the programme } \\
\text {-IEHPs' performance at clinical } \\
\text { placements }\end{array}$ & $\begin{array}{l}\text {-IEHPs } \\
\text {-The educational board } \\
\text {-The bridging managers } \\
\text {-clinical instructors } \\
\text {-*others }\end{array}$ & $\begin{array}{l}\text { Short } \\
\text { Clinical performance of } \\
\text { IEHPsanalysed using a } \\
\text { clinical performance tool }\end{array}$ & 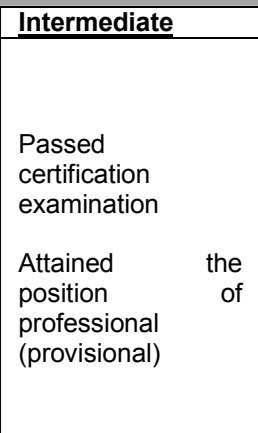 & $\begin{array}{l}\text { More } \\
\text { independent } \\
\text { IEHPs } \\
\text { practitioners }\end{array}$ \\
\hline
\end{tabular}

Note: IEHPs= internationally educated health professionals, 
Step 1- Collecting the relevant information.

Relevant information about the programme to be evaluated should be collected through literature review, document review and ongoing informal interviews with the programme managers. The information is retrieved through an interactive process and based on this information, problem(s) would be described.

\section{Step 2- Describing the problem(s).}

Some authors suggested that in describing the problems, stating and reflecting on the goal of the programme as well as the information obtained in step 1 is foundational (Kaplan \& Garrett, 2005; Millar, Simeone, \& Carnevale 2001). Others argue that for effective description of the problems, the question of "how" should be asked towards the goal of the programme being evaluated (McCawley, 2002; McLaughlin \& Jordan, 2015), and this question would form the overall evaluation question guiding the logic model. For instance, if we are interested in the clinical components of the bridging programme, following the stated goal of the problem above, our overall evaluation question could be "How do the clinical internships of the bridging programme facilitate the success of IEHPs as autonomous/independent practitioners in the healthcare system?"

\section{Step 3- Defining the elements of the logic model.}

As noted above, there are typically four components or levels in a logic model: input, activities, output and outcome. The outcome component may be divided into short, intermediate and long-term outcome. McLaughlin \& Jordan (2015) argued that "customer" someone or a process that uses the outcome - is a crucial part of the logic model; therefore, "customer" was added to the components of the logic model, between output and outcome. The evaluator is expected to clearly list all the possible elements of each of the components identified (Frechtling, 2007; Fitzpatrick et al., 2004). The evaluator should constantly consult the stakeholders throughout the process of identifying and listing the elements in each component. In our context, the stakeholders we would have consulted include the IEHPs, the bridging programme managers, the programme developers, and the clinical preceptors, amongst others. Example of the elements in each of the components for the clinical components of the bridging programme is shown in Table 1.

\section{Step 4- Constructing the logic model.}

In constructing logic model, McLaughlin \& Jordan (2015) recommend that the evaluator should logically use arrows as a process-director to walk the audience through the process and how the elements (defined in step 3 ) and levels are linked to each other. This process should clearly demonstrate how these elements could either solve or provide information that would help solve the different components of logic model of programme being evaluated. There are different ways of constructing and linking the elements in each level. One way is developing areas or pillars of the programme based on the information obtained in step 1. These areas or pillars should be developed through an iterative process of consultation between the evaluators and the stakeholders in the programme. For this hypothetical bridging programme, we developed four areas including admission process, programme curriculum, programme partnership, and a milestone toward entry to work through document review and consultation with stakeholders. Therefore, we based our logic model on these four areas. We have provided a logic model (figure1), as an example of logic model. 


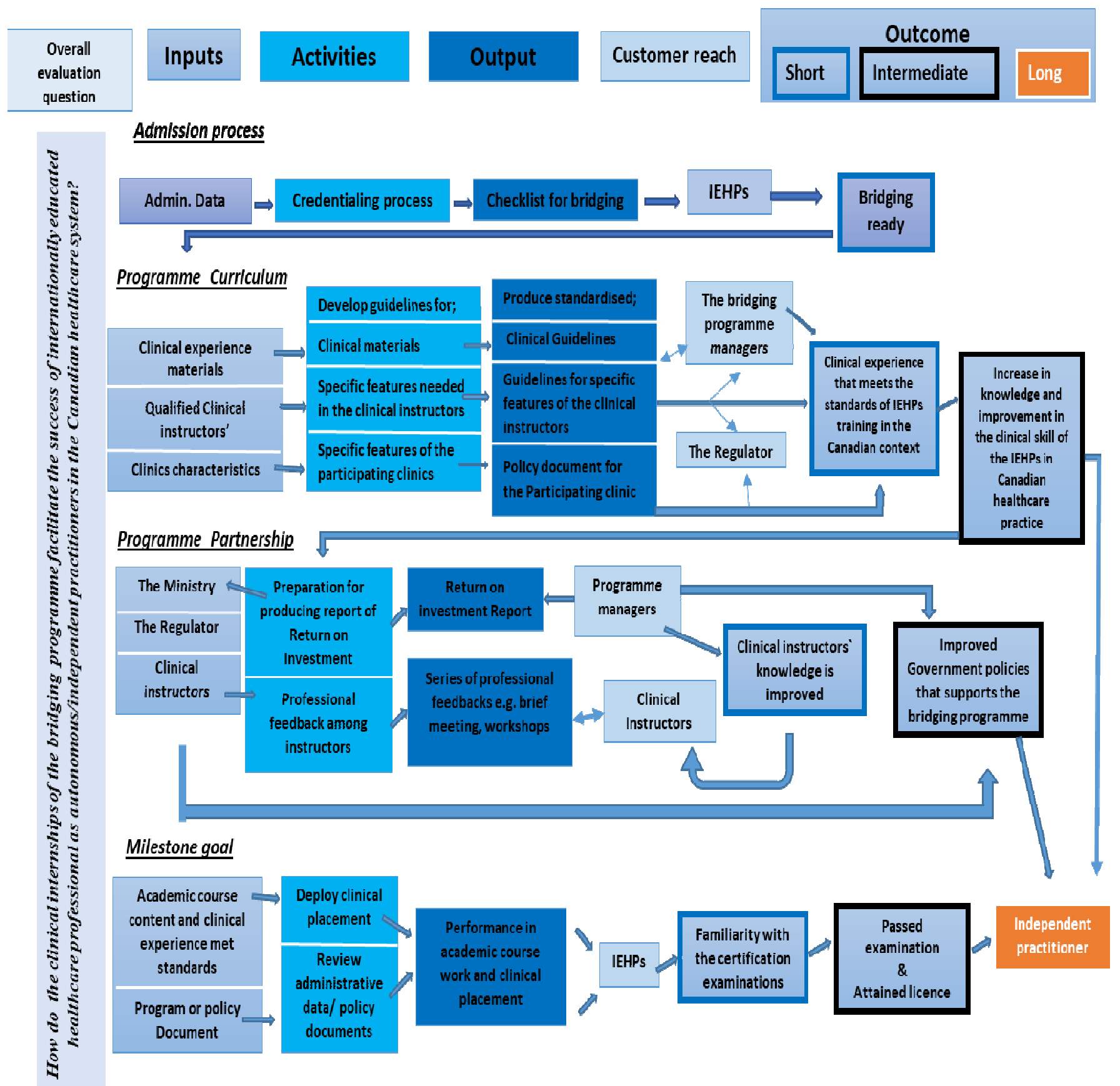

Figure 1: Logic model for the clinical internship of bridging programme

Note: IEHPs= internationally educated healthcare professional, The Ministry- Education Board and The Regulator- licencing board 
Stage 5- Verifying the logic models

Scholars suggested that logic models need to be verified and it requires a thoughtful process which is iterative among the programme evaluators and stakeholders. It often requires randomly asking the question, "How did we get here?" at any element of any component. A clear link or association of how to get at an element of a component should be clear to the evaluators and the stakeholders. For instance, in figure 1, the second output box is "How did we produce clinical guidelines?" Clinical guidelines were produced from events in the activity column. Another example is "How did we increase the knowledge of the IEHPs about healthcare practice in the new country? (1st intermediate, outcome box). Tracing back to the short-term outcome indicates that IEHPs knowledge of healthcare practice was increased because the bridging programme course content includes that promote learners' knowledge about their respective discipline in the new health care context. Any element or box for which the process of tracing back the link does not successfully answer "how did we get there?" requires a further review.

The evaluator's next step is to clearly identify a specific evaluation questions for each component (see Table 2). Each of the questions for each component determines the methods for evaluation. This logic model develops specific evaluation questions for each component and also informs methods of inquiry to be used to answer those question.

\section{CASE STUDY METHODOLOGY FROM A LOGIC MODEL}

Case study methodology is appropriate for a programme evaluation if the programme evaluation fulfils the four criteria described by Yin (2012), such as (a) answering the question of" how", (b) focusing on studying the phenomena in its real-world context, (c) if the boundaries between the context and phenomena are not clear, and (d) if the behaviours cannot be manipulated. We suggest that the specific evaluation questions from the logic model should meet at least 3 of the Yin's criteria listed above.
For instance, our selected evaluation question (described below) met all of the criteria listed above. First, our evaluation question answers "how" the clinical internship influences the IEHPs' performance in the clinical component of the certification examination. Second, the evaluation research focuses on studying the phenomena in its real-world context. This means that the evaluation describes, explores and explains the contextual conditions that occur in natural settings that research instruments, in experimental or cross-sectional studies, cannot. Third, the boundaries between what happens when IEHPs undertake clinical placements in the bridging programme (context), and their experiences and/or performance in the certification examinations (phenomenon) are not clear. Lastly, the behaviour of the IEHPs, the clinicians, and the bridging programme managers cannot be experimentally manipulated.

The steps for conducting a case study evaluation when a research meets at least 3 of Yin's criteria stated above are: (a) stating the evaluation question, (b) providing explanation about the evaluator's epistemological position, (c) defining the study preposition as well as unit of selection, (d) defining the sampling techniques/type, (e) collecting data, (f) conducting analysis, and (g) linking back to logic model.

\section{(a) Stating the evaluation question(s)}

This evaluation question differs from the overall evaluation question. This evaluation question(s) is/are specific to each of the components of the logic model (table 2). We choose to answer the question for the intermediate outcome component - "How do the clinical internships influence the IEHPs' performance in the clinical component of the certification examination?"We recommend that the evaluators provide rationale to support their evaluation question. For instance, in our example, there may be evidence that IEHPs perform poorly in the certification examination; therefore, we explored how the clinical internship has influenced the performance of the IEHPs in the clinical component of the certification examinations. 
Table 2: Showing research questions corresponding to each components/level in the logic model of the BRIDGING program

\section{LOGIC MODEL COMPONENTS INPUTS}

ACTIVITIES

OUTPUT
CUSTOMER REACH

\section{EVALUATION QUESTIONS SPECIFIC TO THE COMPONENTS}

To what extent does the bridging programme have sufficient and good clinical placement properties? Example, duration and location of clinical placement, clinic features.

How do the clinical placement activities enable the IEHPs to develop the competencies needed to practice their healthcare profession in the new country?

How was the IEHPs' performance in the clinical placements during the bridging programme assessed to ensure that the IEHPs are ready to face the certification examination?

What are the experiences of IEHPs and clinical instructors in the bridging programme?

\section{SHORT TERM \\ OUTCOME}

INTERMEDIATE OUTCOME

LONG OUTCOME
TERM

How does the clinical placement influence the IEHPs' performance in the certification examination?

What percentages of IEHPs that complete the bridging programme are practising as an independent healthcare professional in the new country? (b)

\section{Epistemological position}

There are three popular epistemological positions an evaluator could adopt when using case study approach: Post positivism to pragmatism(Yin, 2003), Constructivism (Merriam, 1998), and Constructivism and existentialism (non-determinism) (Stake, 1995). The epistemological position chosen provides the reader and the evaluator with the philosophical underpinning of the case study. Yin believes that case study research questions are well answered using the several components of qualitative and quantitative methods complementairly, while Stakes and Merriam follow the principles similar to qualitative research paradigm. Novice evaluators do not often state the epistemological position or stand of their case study (Baxter \& Jack, 2008). This is problematic because an explicit statement of the epistemological position orients the reader to the process of the evaluation, as well as provides a framework to examine ifthe evaluation question has the necessary coded language associated with the epistemological position chosen (Creswell \&
Poth, 2018). Based on the question we chose, we situated our epistemological position on Yin's principle of pragmatism because we are interested in finding solutions to real-world problems (challenges facing IEHPs in order to practise as an independent professional in a new country); and we believe that diverse approaches of collecting and analysis data would be appropriateto explore how the clinical internships have improved the performance of the IEHPs at the certifiication examinations. These diverse approaches are methods of qualitative and quantitative paradigm in a mixed method approach.

In addition, an evaluator is expected to state and provide rationale for the type of case study evaluation paradigm choosen. While Yin (2012) described different types of case study as single or multiple (embedded) and exploratory, explanatory or descriptive, Stake (1995) described case study as intrinsic based, instrumental or collective case study. A detailed description of these types are beyond the scope of this article (see Yin (2003) and Stake (1995) 
for detailed description of these types). Building on our example of the bridging programme, explanatory, embedded multi-case study is appropriate because (a) our study aimed to explain and link the bridging programme implementation with programme effects (Yin, 2012), and (b) to explore differences within and between the links in the logic model provided in section 1 (Baxter and Jack, 2008).

\section{(c) Study preposition and unit of selection.}

The study proposition should clearly explain the elements in the question that point to what is evaluated. The study proposition statement serves as a focus for data collection, determine direction and scope of the study (Yin, 2003). Specific to our evaluation question, the study proposition statement could be, "The clinical component of the bridgingprogramme could have a strong influence on the IEHPs' performance in the certification examinations." The elements to evaluate include: the scores obtained by the IEHPs when they attempt the clinical component of the certification examinations (quantitative data); the experiences of the IEHPs, preceptors and bridgingprogramme managers with respect to the clinical internship component of the bridging programme(qualitative data).Often times, the study proposition statement is informed by literature reviewand/or informal discussions in the stage 1 and 5 during the logic model development (Calphin-Davies, 2003; Clare \& Van Loon 2003). Professional experience and expertise can be the basis of the study proposition statement if there is no available literature.

The unit of selection refers to what a "case" is in a case study (Abma \& Stake, 2014). In order to determine the "case(s)" in your case study, ask the question of "where". In our study example, we asked "where" the IEHPs attended their clinical internship; and that is aclinic or hospital. In a situation of more than one case, it is expected that the evaluator defines all the possible cases and whether it constitutes a multiple case with embedded units (Yin, 2003). Building from our example, we selected two clinics with embedded units such as IEHPs undertaking internships in an orthopedic unit and an outpatient clinic of the same hospital. Another example is a study conducted by Krupa (2009), in which she described three cases of clients with schizophrenia; although these clients had some similar features, she considered each as an individual case. The choice of what is actually a case is determined by pre-defined criteria for selection.

\section{(d) Sampling techniques/type}

Sampling techniques in case study evaluation process is similar to the sampling techniques employed in the traditional research paradigms. However, purposive sampling is popular for use in case study evaluation process (Yin, 2012). In single case study, most evaluators already know the "case" to study and as such may do sampling within the case, but in multi-case study, sampling is often done at two levels: case level and within case level selection. In our study example, we selected clinics (case level selection) using criterion-I based selection. Subsequently we selected participants within each of the cases to participate in our study (within case level selection) using maximum variation-based selection (Palinkas et al., 2015; Patton, 2002). We suggest that well-defined criteria should guide the sampling techniques at each level. An example of a criterion, for the case level selection in our example, is that the clinics selected must have hosted at least 5 IEHPs since the inception of the bridging programme and/or must have at least 3 IEHPs presently on a clinical internship. For the within case level selection, IEHPs participants selected should vary in terms of gender, countries of entry-level training, years of practice outside Canada of the selected IEHPs and those that have attempted and passed/failed the certification examinations. Other features of participants may be relevant in other programme evaluation designs or contexts.

\section{(e) Data collection}

Researchers recommended multiple data collection for any type of case study evaluation, because of three reasons: a good source of triangulation, creation of a case study database and maintenance of a chain of evidence (Yin, 2012; Merriam, 1998; Stake, 1995). Ballbach (1999) and Krupa (2000) suggested that developing a case study protocol is the easiest way to ensure that relevant and directed data is 
collected. Table 3 shows an example of a case study protocol. Yin (2012) suggested that data can be collected from (a) documents (letters, agendas, and progress reports), (b) archival/administrative records (service records, organisational charts, budgets etc.), (c) interviews (typically open-ended, but also focused, structured and surveys are possible), (d) direct observations (formal or casual; useful to have multiple observers), (e) participant observation (assuming a role in the situation and getting an inside view of the events), and (f) physical artifacts (if necessary).

Table 3: Case study protocol: question, specific details and sources of data collection

\begin{tabular}{|c|c|c|}
\hline Questions & Details & Source of data collection \\
\hline $\begin{array}{l}\text { What is the "case"- } \\
\text { Case description? }\end{array}$ & $\begin{array}{l}\text { - Description of the physical structure of the } \\
\text { clinics (location, setting and type of patient } \\
\text { care) } \\
\text { Description of the characteristics of the } \\
\text { IEHPs (demographics) } \\
\text { Description of the characteristics of the } \\
\text { clinical preceptors (years of experience, area } \\
\text { and settings of practice) } \\
\text { Description of the characteristics of the } \\
\text { bridging managers especially those in direct } \\
\text { contact with the IEHPs during the bridging } \\
\text { programme }\end{array}$ & $\begin{array}{l}\text { Administrative document such as } \\
\text { programme policy, interviews and } \\
\text { observations }\end{array}$ \\
\hline $\begin{array}{l}\text { What are the } \\
\text { experiences } \\
\text { IEHPs? }\end{array}$ & $\begin{array}{l}\text { - How do the IEHPs' experience at the clinics } \\
\text { help them to prepare for the certification } \\
\text { examinations? } \\
\text { What are the IEHPs' general view of the } \\
\text { clinical placements during the bridging } \\
\text { programme } \\
\text { What can the IEHPs change in the clinical } \\
\text { components of the bridging programme? }\end{array}$ & $\begin{array}{l}\text { Interviews (individuals or focus), } \\
\text { Direct observation, document review- } \\
\text { annual report. }\end{array}$ \\
\hline $\begin{array}{l}\text { What are the } \\
\text { experiences of the } \\
\text { clinical preceptors? }\end{array}$ & $\begin{array}{l}\text { - Can you describe your experience in } \\
\text { supervising the IEHPs in your clinic? } \\
\text { What are the day to day skills and activities } \\
\text { that you evaluate in the IEHPs in your clinic? } \\
\text { Are their specific problems or patterns that } \\
\text { you have observed since you started } \\
\text { accepting IEHPs in your clinic? } \\
\text { How do your review the IEHPs clinical } \\
\text { performance at the end of their clinical } \\
\text { placement? }\end{array}$ & $\begin{array}{l}\text { Interview, direct observation, } \\
\text { document reviews- log in sheet and } \\
\text { performance review sheet. }\end{array}$ \\
\hline $\begin{array}{l}\text { What are the } \\
\text { experiences of the } \\
\text { bridging programme } \\
\text { managers? }\end{array}$ & $\begin{array}{l}\text { - Can you describe the process of choosing } \\
\text { clinical placement center by the IEHPs? } \\
\text { What factors influences clinical placement } \\
\text { choices by the IEHPs? } \\
\text { - What are the strategies to ensure that IEHPs } \\
\text { are actually gaining the experience required } \\
\text { to practise as an independent healthcare } \\
\text { professional in Canadian context? }\end{array}$ & $\begin{array}{l}\text { Interviews, document } \begin{array}{r}\text { analysis, } \\
\text { administrative } \\
\text { performance sheet. }\end{array}\end{array}$ \\
\hline
\end{tabular}

Source: Modified from Balbach, (1999) and Krupa (2000). IEHPS= internationally educated healthcare professionals 
(f)

Data analysis

Different schools of thought exist for data analysis in a case study methodology and the choice depends on the type of case study evaluation: qualitative or mixed method. Typically, the detailed process of the analysis follows the same pattern of a classical data analysis techniques of qualitative, quantitative and mixed method (Yin, 2012). Yin (2003) described 2 general analytic principles: data analysis informed by (a) the evaluator's study proposition statement, and (b) a descriptive framework like logic model. Either or both of these principles can use the basic four techniques for analysis: pattern matching, explanation building, time-series analysis, and cross-case synthesis (Yin, 2012). Below we provided a detailed example of how to analyse data in a case study methodology drawing experiences from the literature.

Based on the data collection pattern and on features of the multi-case method of our study example, we propose a data analysis process to be done in three phases. In brief, phase one is the initial analysis of the quantitative and qualitative data separately. Phase two is a correlation model analysis, a variation of embedded design where the qualitative data are embedded within a quantitative design to help explain the outcomes of the correlation model (Creswell \& Piano-Clark (2007). Phase three requires using Yin's two levels for case study analysis to interpret the data.

In phase one, the quantitative data would be analysed using statistics to describe IEHPs' scores on the certification examination and, if warranted, to infer differences in scores before and after IEHPs have completed the bridging programme. However, the qualitative data would be analysed using an interpretive analysis. The interpretive analysis is an iterative and inductive process of decontextualisation and recontextualisation of data (Ayres, Kavanaugh, \& Knafl, 2003). During decontextualisation, we would separate data from the original context of each of the individual cases and within cases. We would assign codes to units of meaning in the texts. In contextualisation, we would examine each of the assigned codes for patterns and then would reintegrate, organise and reduce the data around central themes as described by Starks
(2007). The qualitative information from each of the cases is analysed separately. For instance, in one clinic where IEHPs undertake internships, the observational data, the interviews, and the document reviews would be analysed separately and later merged. At the end of the qualitative data analysis in this phase, relationships in the central themes would be explored across all the cases and narratives.

In phase two, an embedded model analysis as described by Creswell \& Piano-Clark (2007) would be employed. The model uses the quantitative data to support the qualitative data. Specifically, the quantitative analysis would be related to the themes generated from the qualitative data.

Lastly in phase three, Yin's two levels of case study data analysis and interpretation would be employed (Yin, 2003). His two levels were later divided into four strategies (case description, study proposition guiding analysis, pattern matching techniques and rival explanations) for easy understanding (Yin, 2009). First, the analysis would be organised based on the description of the general characteristics and relation of the phenomena in question (case description). A general analytic strategy specifically describing the elements of the clinical internships in the bridging programme would be adopted. However, we would revisit the elements in the logic model in Table 2. Second, more specific analytic techniques would be employed. We would adopt a pattern matching technique, which allows us to describe and explain if the expected outcome as a pattern was found. For instance, we could explore if clinical internship elements have a pattern(s) that can be linked to IEHPs' performance in the certification examinations.

We would develop a cross-case analysis for literal replication between the two cases as described by Yin (2003). We would employ an iterative process to ensure that the categories of each of the case studies create emerging themes that correspond to the evaluation question. At the end of the analysis, we would develop linkages between the emerging themes and the phenomena under study using axial coding. At the end the themes from the study would be linked back to the logic model. 


\section{LINKING BACK TO THE LOGIC MODEL}

We suggest that it is appropriate for evaluators to link their theme back to the logic model as suggested by Yin (2003). Depending on the type of case study evaluation process the evaluator employed, discussing the result is appropriate to ensure that the evaluator maps the themes across the logic model. For instance, in our study, the logic model (figure 1), we hoped to answer the evaluation question specific to intermediate outcomes. The themes from our case study results should clearly address our four areas of the logic evaluation process: admission process, programme curriculum, programme partnership and milestone goals. Are there specific themes that provided information on (a) the characteristics of "bridgeable" candidates (admission process), (b) the quality of the clinical experience of the IEHPs and how these experiences meets the standards of healthcare professional training in the new country's context (programme curriculum), (c) clinical instructors' characteristics and knowledge over time as they supervise IEHPs in the clinical internships (programme partnership), and (d) how IEHPs are familiar with what is expected of them in the certification examinations (milestone goal)? Linking the themes back to logic model typically follows the pattern matching process describe by Yin (2013).

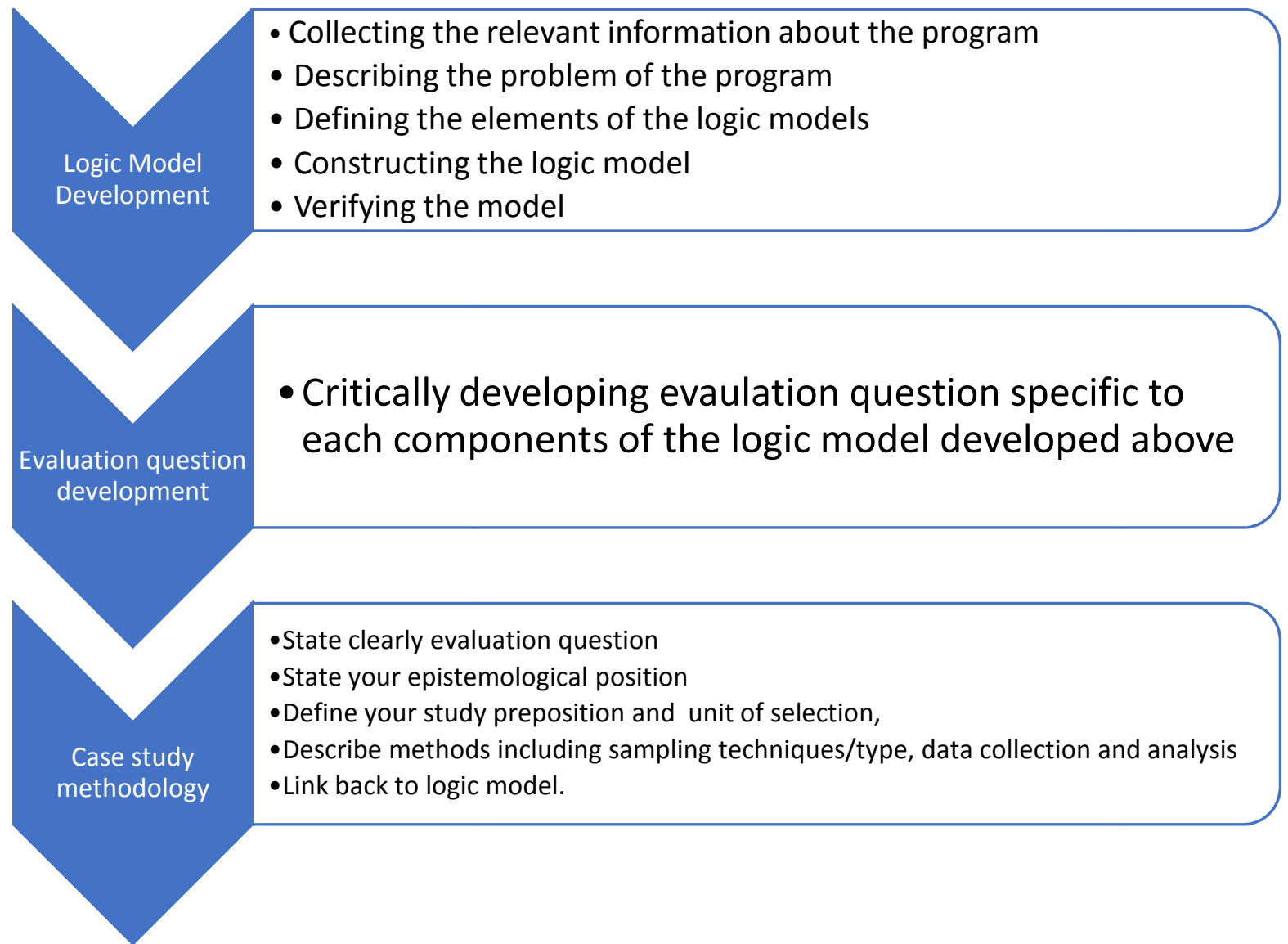

Figure 2: Steps in developing logic model to inform a case study evaluation methodology. 
CONCLUSION

We provided a diagram (figure 2) to highlight the step by step process of advancing from logic model to case study methodology. We believe this would provide a pictorial guidance for early evaluators when they conceptualised and design their evaluation projects.

\section{REFERENCES}

Abma, T and Stake, R., 2014. Science of the particular: An advocacy of naturalistic case study in health research. Qualitative Health Research, 24 (8), 1150-1161. DOI: $10.1177 / 1049732314543196$.

Ayres, L., Kavanaugh, K and Knafl, K., 2003. Within-case and across-case approaches to qualitative data analysis. Qualitative Health Research, 13, 871-883. doi.org/10.1177/1049732303013006008.

Balbach, E., 1999. Using case studies to do program evaluation. Sacramento, CA: California Department of Health Service.

Baxter, P and Jack, S., 2008. Qualitative case study methodology: Study design and implementation for novice researchers. The Qualitative Report 13(4), 544-559. Retrieved from http://nsuworks.nova.edu/tqr/vol13/iss4/2

Calpin-Davies, P., 2003. Management and leadership: a dual role in Nursing education. Nurse Education Today 23 (1), 3-10. doi.org/10.1016/S02606917(02)00157-0.

Clare, J and Van Loon, A., 2003. Best practice principles for the transition from student to registered nurse. Collegian, 10(4), 2531. doi.org/10.1016/S13227696(08)60073-6.

Cooksy, L., Gill, P and Kelly, A., 2001. The program logic model as an integrative framework for a multi method evaluation. Evaluation and Program Planning.
24(2),119-128. doi.org/10.1016/S01497189(01)00003-9.

Creswell, J and Piano-Clark, V., 2007. Choosing a mixed method design. Designing and conducting mixed methods research. Thousand Oaks, CA: SAGE Publications.

Creswell, J. W and Poth, C. N., 2018. Qualitative inquiry \& research design: Choosing among five approaches ( $4^{\text {th }}$ ed.). Thousand Oaks, CA: SAGE publications.

Frechtling, J., 2007. Logic Modeling Methods in Program Evaluation. San Francisco, CA: Jossey-Bass.

Fitzpatrick, J., Sanders, J and Worthen, B., 2004. Program evaluation: Alternative approaches and practical guidelines $\left(3^{\text {rd }}\right.$ ed.). Boston: Pearson.

Frye, A and Hemmer, P., 2012. Program Evaluation models and related theories: AMEE guide no 67'. Medical Teacher 34, e228-e229. doi: $10.3109 / 0142159 X .2012 .668637$.

Kaplan, S and Garrett, K., 2005. The use of logic models by the community-based initiatives. Evaluation and Program Planning. 23(2), 167-172. doi.org/10.1016/i.evalprogplan.2004.09.0 02.

Krupa, T., 2000. Work Recovery in Schizophrenia. PhD Thesis, Department of Human Development and Applied Psychology, Ontario Institute for Studies in Education, University of Toronto, Canada.

McCawley, P., 2002. The Logic Model for Program Planning and Evaluation. University of Idaho Extension. Available online at https://www.d.umn.edu/ kgilbert /educ5165-731/Readings/The\%20Logic \%20Model.pdf.

McLaughlin, J and Jordan, G., 2015. Using Logic Model. In Newcomer, K., Hatry, $\mathrm{H}$ and 
Wholey, $J\left(^{\text {th }}\right.$ edition $)$ Handbook of Practical Program Evaluation. USA: Jossey-Basses Wiley.

Merriam, B., 1998. Qualitative Research and Case Study Applications in Education. San Francisco, CA: Jossey-Bass.

Millar, A., Simeone, R and Carnevale, J., 2001. Logic models: a systems tool for performance management. Evaluation and Program Planning. 24(1):73-81. II: S0149-7189(00)00048-3.

Owston, R., 2008. Models and Methods for Evaluation. Handbook of Research on Educational Communications and Technology pages 605-617. Available online at htpp://www.edtech2.boiestate.e du/shobhanaganapathi/505/Models $\% 20 a$ nd\%20Methods\%20for\%20Evaluation.pd f.

Palinkas, L., Horwitz, S., Green, C., Wisdom, J., Duan, N and Hoagwood, K., 2015. Purposeful Sampling for Qualitative Data Collection and Analysis in Mixed Method Implementation Research. Adm Policy Ment Health 42(5): 533-544. doi: $10.1007 / \mathrm{s} 10488-013-0528-y$

Patton, Q., 2002. Qualitative Research and Evaluation Methods. 3rd edition, Thousand Oaks, CA: SAGE Publications.

Posavac, E and Carey, R., 2007. Program evaluation: Methods and case studies ( $7^{\text {th }}$ edition). Upper Saddle River, NJ: Prentice Hall.
Stake, R. E., 1995. The art of case study research. Thousand Oaks, CA: SAGE Publications.

Starks, H., 2007. Choose Your Method: A Comparison of Phenomenology, Discourse Analysis, and Grounded Theory. Qualitative Health Research 17 (10): 13721380.10.1177/1049732307307031.

Switzer-McIntyre, S., Bonnyman, A and Quesnel, M., 2015. Bridging for success: lessons learned by the Ontario internationally educated physiotherapy bridging program. Physiotherapy 101 (suppl.1): e1462e1463. doi:10.1016/j.physio.2015.03.143 0

Yin, R., 2012. Application of case study research. $3^{\text {rd }}$ edition, London: SAGE Publications.

Yin, R., 2009. Case study research: Design and methods. 4th edition, Thousand Oaks, CA: SAGE Publications.

Yin, R., 2003. Case Study Research: Design and methods. $3^{\text {rd }}$ edition, Thousand Oaks, CA: SAGE Publications. 